\title{
Time to improve the communication of evidence- based medicine to pregnant women: a review of an exemplary framework related to the prevention of gestational diabetes
}

Birgit Arabin ( $\square$ bine.clara.angela@gmail.com )

Philipps-Universitat Marburg https://orcid.org/0000-0002-0492-4425

\section{Susann Behnam}

Philipps-Universitat Marburg

Christin Ellermann

Max-Planck-Institut for Human Development Harding Center

Mirjam A Jenny

Max-Planck-Institute for Human Development Harding Center

\section{Debate}

Keywords: Maternal obesity, gestational diabetes, health literacy, communication, evidence-based medicine

Posted Date: September 4th, 2019

DOl: https://doi.org/10.21203/rs.2.13891/v1

License: (1) This work is licensed under a Creative Commons Attribution 4.0 International License.

Read Full License 


\section{Abstract}

BACKGROUND Medical specialists are frequently challenged to understand and explain the best evidence even when study results are contradictive. During pregnancy, communication of evidence should motivate women to realize life style changes in favor of themselves and their offspring. MAIN BODY On the topic of prevention of gestational diabetes alone, we found 17 systematic reviews/meta-analyses. Outcomes, reporting and methodological quality differed according to PRISMA, ROBIS and AMSTAR tools. CONCLUSIONS We propose a methodology to select and transform the best evidence into a format illustrating benefits and harms of interventions as fact boxes and icon arrays, which may be applied in other fields of obstetrics.

\section{Background}

Gestational diabetes mellitus (GDM) is defined as glucose intolerance first diagnosed in pregnancy (1). In 2012 , the prevalence of GDM was $17.8 \%$ with a range of $9.3-25.5 \%$ (2). GDM is associated with elevated risks for pre-eclampsia, perinatal mortality, fetal macrosomia, shoulder dystocia or cesarean delivery. Metzger et al. already reported on abnormal maternal postpartum glucose tolerance requiring early and continuing follow-up of all women with GDM (3). Later in life, increased hyperinsulinemia, dyslipidemia, type-2 diabetes mellitus (DM II), hypertension, and cardiovascular disease (CVD) were described (4). Glucose resistance appears earlier in obese women due to pre-existing impaired insulin resistance. Overweight, obesity and excessive gestational weight gain (EGWG) (5) as explained as a weight gain of > $0.27 \mathrm{~kg} /$ week or even $>0.41 \mathrm{~kg} /$ week (6) are all associated with increased risks of GDM. An individualized prediction is provided by first trimester algorithms with a sensitivity of up to $80 \%(7-10)$ pointing towards pre-existing risk-profiles that lower the threshold for the disease (11-13). The risk to develop overt DM after a pregnancy with GDM increases with age resulting in a cumulative 15 year risk of $25 \%(14)$.

Barker et al. postulated that the global incidence of GDM mainly depends on a mismatch between the pre-and postnatal environment (15) determining the increasing prevalence in regions with previously low rates of GDM. There is an U-shaped relation between low (OR 2.15, 95\% Cl 1.29-3.50) and high BW (OR: 1.97, 95\% Cl: 1.12-3.45) and subsequent GDM in females (16). Prenatal famine exposure and fetal growth restriction (FGR) were associated with impaired glucose tolerance, proinsulin and insulin secretion in adulthood (17-19), but also fetal macrosomia associated with GDM increases the risk of childhood obesity (20) both as compared to controls. Hypertriglyceridemia was diagnosed in 14/68 children (21\%) before puberty (21). At the age of 11 years, the risk for metabolic syndrome was 3.6-fold higher (22). As adults, the risks of insulin resistance and metabolic syndrome $(21,23), C V D$, insulin-dependent DM and early mortality (24) are increased. Offspring with FGR of mothers with GDM had also increased risks for metabolic syndrome: aOR 1.29 (95\% Cl 1.24-1.35) (25).

The rising global rates of overweight, obesity, GDM and type-Il diabetes require urgent consideration by policy makers and awareness of physicians and future parents. Therefore, health care providers should 
translate the evidence into formats recognizable for lay people. In this perspective, we evaluated current systematic reviews (SRs) and meta-analyses to reduce GDM and present a framework for communication. In other fields of medicine, it has been shown that fact boxes and icon arrays can enable patients without medical or statistical background to make informed decisions $(26,27)$ by presenting benefits and harms (28-30). It would be ideal if improved health literacy obtained during pregnancy would help mothers to maintain a healthier life style and improve the health of their offspring.

\section{Main Text}

\section{Selection of the best evidence}

Already the term "systematic review and meta-analysis" seems to suggest a magic "state of the art". However, SRs and meta-analyses may show contradictive results. This is difficult to understand for clinicians involved in counselling and even more for their patients. Meanwhile, statisticians or researchers produce a flash flood of SRs about clinical procedures which they might have never performed involving randomized controlled trials (RCTs) from health care systems they are not familiar with. Senior clinicians who do not necessarily have the time for research are expected to follow the conclusions although these may differ from their daily good medical practice (GMP). Whether GMP was at all considered within RCTs of SRs is retrospectively difficult to determine and frequently not analyzed. There is a need for transparency how to determine clinical protocols and audit procedures, to select the best evidence, to exclude studies prone for bias and to transform results of RCTs, SRs and meta-analyses of different quality into messages which are of benefit for our patients, e.g. mothers and their offspring.

By performing a literature search up to December 2018 utilizing Medline, Web of Science and the Cochrane Library related to the prevention of GDM and using search terms: pregnancy, overweight, obesity, weight gain, diabetes, GDM, perinatal mortality, systematic reviews and meta-analysis we identified 17 meta-analyses and systematic reviews using GDM as a primary outcome:

- 6/17 investigated only dietary counselling (31-36),

- 4/17 only supervised exercise programs (37-40),

- 7/17 combined dietary and physical exercise interventions (41-47).

All intervention participants had been tested versus groups with standard care. Only 6/17 studies used macrosomia or large for gestational age (LGA) as primary or secondary outcome, 4/17 looked for perinatal mortality (46). In 14/17 publications all maternal BMI categories were considered, 2 SRs exclusively concentrated on pregnant women with overweight and obesity $(31,42)$, only $1 / 17$ on normal weight women (32). Several RCTs were cited more than once. Therefore, a summary of all SRs would cause a bias. Categorizing investigated lifestyle interventions showed varying results:

- Among 6 SRs investigating only dietary advice only one SR with women and a BMl $>25 \mathrm{~kg} / \mathrm{m} 2$ reported that the intervention significantly reduced GDM in accordance with a sub-analysis of 
women with a $\mathrm{BMI}>25 \mathrm{~kg} / \mathrm{m} 2$ within another publication (30). One SR investigating a low-glycemic index diet found a decreased rate of LGA children (36). Other significant outcome variables were a reduction of maternal weight gain (4/6 SRs), of pregnancy-related hypertension (2/5 SRs), fasting and postprandial glucose and post-partum weight retention (both in 1/6 SRs).

- Among 4/17 SRs investigating physical activity and exercise programs during pregnancy 3/4 found a significant reduction of GDM, 2/4 showed a significant reduction of gestational weight gain in mothers stimulated to exercise and 1/4 a significant reduction of LGA infants.

- Among 7/17 SRs investigating counselling of both physical exercise and diets, 2/7 found a significant reduction of GDM when the interventions started early and 4/7 described a significant reduction of maternal weight gain during pregnancy.

To extract the best evidence we analyzed the reporting and methodological quality of the publications using the PRISMA (48), ROBIS (49), AMSTAR-1 (50) and AMSTAR-2 tools (51) to design a fact box with a corresponding icon array to make the information accessible to those who are less familiar with a tabular format. Fact boxes contain a description of the reference class, a comparison of at least two groups, the effects in absolute numbers, and a summary of benefits and harms (52). Their development follows evidence-based medicine according to Sackett et al. (53). Fact boxes may help patients to understand the evidence in case of medical uncertainty independently of the opinion of their health care providers who tend to deny uncertainty, downplay risks and overstate benefits of interventions (54). Several RCTs have shown that fact boxes and icon arrays are effective tools for informing lay people. In addition, they may improve the understanding of statistical data and of benefits and harms by relating the data to a group of 100 or 1000 participants (52). Although we already suggested to use fact boxes, albeit not in combination with icon arrays $(55,56)$, these tools have not yet been integrated in maternalfetal medicine.

Within a stepwise evaluation, only 4/17 SRs fulfilled all by PRISMA demanded reporting quality items for registration, study question, literature search, data abstraction, and result evaluation. Only these SRs and meta-analyses are summarized in Table 1 for dietary intervention (35), exercise (38) and the combination of dietary and exercise counselling $(44,47)$. Using ROBIS criteria all 4 SRs were characterized as "low risk of bias". None of the SRs explicitly explained why only RCTs were integrated which is 1/16 AMSTAR-2 criteria; thus only 2 SRs received 15/16 "YES" answers by the AMSTAR-2 criteria although 11/11 AMSTAR-1 points $(35,44)$. From these remaining two SRs we chose the study of Tieu et al. to create a fact box and icon array because it concentrated on only one intervention which facilitated interpretation of the findings for lay people (35).

Figure 1 illustrates that dietary counselling in pregnant women had no significant impact on the prevention of GDM, although there was a trend to reduce GDM based on low quality studies. However, about $10 / 100$ pregnant women without, but only 3/100 women with nutritional counselling developed high blood pressure which means that in about $7 / 100$ women hypertensive disorders in pregnancy (HDP) could be prevented. When the exact numbers of two groups differ, non-significant differences can appear 
as relevant group differences. Contrary to previous papers, we therefore now present the absolute number of the control group instead of the lowest number.

\section{Specific interventions}

The fact box shows that dietary counselling did not increase risks but reduced HDP (Figure 1). This general information can be expanded by details from singular RCTs:

\section{Dietary counselling}

The components of women's diets influence GDM risks (57). Consumption of sugar-sweetened drinks, potatoes (58), animal fat and cholesterol (59), high glycemic load and low-cereal fiber diets (60) are associated with a risk of GDM. Alternatively, a high-fiber diet (60), intake of vegetables, a substitution of red meat by poultry, fish, or legumes (61) and of potatoes by vegetables (58) and adherence to "healthful" dietary patterns (62) are also associated with a lower risk of GDM.

\section{Physical exercise counselling}

There are large differences in the proportion of women performing regular exercise before and during pregnancy. In Norway, the rate before pregnancy was $46.4 \%$, but declined to $28 \%$ and $20 \%$ at 17 and 30 gestational weeks respectively (63). Studies in Denmark (64), the USA (65) or Brazil (66) showed a more pronounced reduction in physical activity even in uncomplicated pregnancies whereby activity positively correlated with the income. Most women do not meet recommendations for physical activity (66). Timing, intensity or kind of exercise (e.g. swimming, running or aerobics) within 4/17 SRs and meta-analyses was not specified and the compliance not controlled.

\section{Combined counselling}

Similarly, the overall and differential effects of combined diet and physical activity during pregnancy varied by the pattern, timing and the prevalence of exercise or nutrition.

\section{Pharmacological counselling}

Systematic reviews and meta-analyses to prevent GDM as a primary outcome. have involved metformin in obese women (67), myo-inositol (68) and probiotics (69). Metformin could decrease gestational weight gain but not GDM or perinatal mortality. Pregnant women should not use metformin to prevent GDM or poor pregnancy outcomes in obese non-diabetic women. In contrast, in women who are already diagnosed with GDM, metformin reduces HDP when compared with other treatments or placebo (70). 
Four RCTs on antenatal supplementation with myo-inositol during pregnancy showed a potential benefit to reduce GDM. There were no differences for HDP, macrosomia or perinatal mortality when compared with controls. Only one RCT has shown a reduction in GDM when women used probiotics without data on HDP or fetal outcomes (69).

\section{Conclusion}

Strength of this narrative review is to increase awareness towards the increasing number and the quality of retrospective SRs and meta-analyses. Recently, Shennan indirectly criticized a lack of consistent primary evidence in so-called network meta-analyses which compare interventions of different quality studied at different places and times (71). Similarly, Prior published in this journal on "p-hacking" characterizing meta-analyses with a selection bias due to absent or delayed registration of the protocol or non-consistent outcome parameters (72). Nevertheless, this paper is insufficiently debated in the public. Another potential error is to apply Cochrane tools for RCTs which contain an item of blinding participants and personnel. This item is of limited value or even confusing for lifestyle interventions, since neither counselling health care specialists nor women following a diet or exercise program can be blinded (73).

Limitations of this review include that we could only summarize retrospective SRs, only 2/17 designed as an individual participant data meta-analysis $(33,47)$. Not all studies applied a sensitivity analysis. In addition, it has not yet been shown that fact boxes improve the understanding of parents-to be and the dialogue between them and their health care providers as demonstrated for other fields of medicine. Therefore, we are currently examining the acceptance in different social and patient groups.

We consciously concentrated on lifestyle interventions because a change in behavior during the sensitive period of pregnancy might convince women to play an active part in the health outcomes of themselves and their children. Pregnant women are particularly often in contact with the medical system and could be periodically informed about diet and exercise which are not associated with potentially undiscovered harms as compared to pharmacologic interventions.

In the future, prospective meta-analyses and Delphi procedures as already performed for GDM (74) may avoid weaknesses of retrospective SRs and improve the sources for counselling. Further studies should demonstrate whether increased awareness and compliance towards evidence-based counselling translates into better compliance or better outcomes of mothers and their offspring. In the meantime, editorial boards might critically analyze SRs and meta-analyses, so that only the best evidence is accepted and translated into patient counselling. Fact boxes and icon arrays could supplement the stateof-the-art of clinical research and guidelines for parents who must make decisions for or against screening tools, invasive procedures, medical treatments or the place of birth. This would allow women to be more independent of their health care providers' views who may be biased by false incentives (75). Practices to increase the health literacy of pregnant women should become part of medical education. Finally, illustrations of essential information may help policy makers to decide whether the introduction of 
interventions would fulfill the "Triple Aim" criteria to reduce costs and still increase individual satisfaction and the health of a society (76).
Abbreviations
BMI Body mass index,

$\mathrm{Cl}$ Confidence interval

CVD Caridovascular disease,

DM Diabetes mellitus

EGWG Gestational weight gain,

FGR Fetal growth restriction

GDM Gestational diabetes mellitus

HDP Hypertensive diseases in pregnancy

IOM Insitute of Medicine

LGA Large for gestational age

OR Odds ratio

RCT Randomized controlled trail

RR Relative risks

SGA Small for gestational age

SR Systematic review 


\section{Declarations}

Ethic approval and consent to participate: Not apüplicable

Consent to publish: Achieved by all authors

Availability of data and material: see refrences, otherwise not applicable.

Supporting data can be obtained from the references an if required from the authors.

Competing interest: The authors report no conflict of interests with respect to financial support of this work.

Funding: No funding

Authors Contribution: BA designed the manuscript and wrote the essentials of the text. SB performed the literature search and supported the classification of the 17 SRs / meta-analyses, CE and MJ designed the fact box and icon array, all authors have studied and revised the manuscript. All authors accept responsibility for the paper as published.

Acknowledgement: We thank Prof. Gerd Gigerenzer and Dr. Jens Stupin for inspiration and support by continuous discussions.

\section{References}

1.Wiener K. Identifying gestational diabetes mellitus and the effect of different diagnostic criteria. Journal of obstetrics and gynaecology: the journal of the Institute of Obstetrics and Gynaecology. 2001;21(2):158-9.

2.Sacks DA, Hadden DR, Maresh M, Deerochanawong C, Dyer AR, Metzger BE, et al. Frequency of gestational diabetes mellitus at collaborating centers based on IADPSG consensus panel-recommended criteria: the Hyperglycemia and Adverse Pregnancy Outcome (HAPO) Study. Diabetes care. 2012;35(3):526-8.

3.Metzger BE, Bybee DE, Freinkel N, Phelps RL, Radvany RM, Vaisrub N. Gestational diabetes mellitus. Correlations between the phenotypic and genotypic characteristics of the mother and abnormal glucose tolerance during the first year postpartum. Diabetes. 1985;34 Suppl 2:111-5.

4.Arabin B, Baschat AA. Pregnancy: An Underutilized Window of Opportunity to Improve Long-term Maternal and Infant Health-An Appeal for Continuous Family Care and Interdisciplinary Communication. Frontiers in pediatrics. 2017;5:69.

5.Rasmussen KM, Abrams B, Bodnar LM, Butte NF, Catalano PM, Maria Siega-Riz A. Recommendations for weight gain during pregnancy in the context of the obesity epidemic. Obstetrics and gynecology. 
2010;116(5):1191-5.

6. Hedderson MM, Gunderson EP, Ferrara A. Gestational weight gain and risk of gestational diabetes mellitus. Obstetrics and gynecology. 2010;115(3):597-604.

7.Cuckle HS. Screening for pre-eclampsia-lessons from aneuploidy screening. Placenta. 2011;32 Suppl:S42-8.

8.Gabbay-Benziv R, Doyle LE, Blitzer M, Baschat AA. First trimester prediction of maternal glycemic status. Journal of perinatal medicine. 2014;43(May;(3)):283-9.

9.Gabbay-Benziv R, Oliveira N, Baschat AA. Optimal first trimester preeclampsia prediction: a comparison of multimarker algorithm, risk profiles and their sequential application. Prenatal diagnosis. 2016;36(1):34-9.

10.Nanda S, Savvidou M, Syngelaki A, Akolekar R, Nicolaides KH. Prediction of gestational diabetes mellitus by maternal factors and biomarkers at 11 to 13 weeks. Prenatal diagnosis. 2011;31(2):135-41.

11.Fleming N, Ng N, Osborne C, Biederman S, Yasseen AS, 3rd, Dy J, et al. Adolescent pregnancy outcomes in the province of Ontario: a cohort study. Journal of obstetrics and gynaecology Canada: JOGC = Journal d’obstetrique et gynecologie du Canada: JOGC. 2013;35(3):234-45.

12.Rich-Edwards JW, McElrath TF, Karumanchi SA, Seely EW. Breathing life into the lifecourse approach: pregnancy history and cardiovascular disease in women. Hypertension. 2010;56(3):331-4.

13.Sattar N, Greer IA. Pregnancy complications and maternal cardiovascular risk: opportunities for intervention and screening? BMJ. 2002;325(7356):157-60.

14.Ashwal E, Hadar E, Hod M. Diabetes in low-resourced countries. Best practice \& research Clinical obstetrics \& gynaecology. 2015;29(1):91-101.

15.Barker DJ, Osmond C, Golding J, Kuh D, Wadsworth ME. Growth in utero, blood pressure in childhood and adult life, and mortality from cardiovascular disease. BMJ. 1989;298(6673):564-7.

16.Claesson R, Aberg A, Marsal K. Abnormal fetal growth is associated with gestational diabetes mellitus later in life: population-based register study. Acta obstetricia et gynecologica Scandinavica.

2007;86(6):652-6.

17.de Rooij SR, Painter RC, Phillips DI, Osmond C, Michels RP, Godsland IF, et al. Impaired insulin secretion after prenatal exposure to the Dutch famine. Diabetes care. 2006;29(8):1897-901.

18.Persson B, Pschera H, Binder C, Efendic S, Hanson U, Hartling S, et al. Decreased beta-cell function in women with previous small for gestational age infants. Hormone and metabolic research $=$ Hormon- und Stoffwechselforschung = Hormones et metabolisme. 1993;25(3):170-4. 
19.Roseboom T, de Rooij S, Painter R. The Dutch famine and its long-term consequences for adult health. Early human development. 2006;82(8):485-91.

20.Simmons R. Perinatal programming of obesity. Experimental gerontology. 2005;40(11):863-6.

21.Keely EJ, Malcolm JC, Hadjiyannakis S, Gaboury I, Lough G, Lawson ML. Prevalence of metabolic markers of insulin resistance in offspring of gestational diabetes pregnancies. Pediatric diabetes. 2008;9(1):53-9.

22.Boney CM, Verma A, Tucker R, Vohr BR. Metabolic syndrome in childhood: association with birth weight, maternal obesity, and gestational diabetes mellitus. Pediatrics. 2005;115(3):e290-6.

23.Dabelea D, Knowler WC, Pettitt DJ. Effect of diabetes in pregnancy on offspring: follow-up research in the Pima Indians. The Journal of maternal-fetal medicine. 2000;9(1):83-8.

24.Rich-Edwards JW, Fraser A, Lawlor DA, Catov JM. Pregnancy characteristics and women's future cardiovascular health: an underused opportunity to improve women's health? Epidemiologic reviews. 2014;36:57-70.

25.Stuart A, Amer-Wahlin I, Persson J, Kallen K. Long-term cardiovascular risk in relation to birth weight and exposure to maternal diabetes mellitus. International journal of cardiology. 2013;168(3):2653-7.

26.Marteau TM, Dormandy E, Michie S. A measure of informed choice. Health expectations: an international journal of public participation in health care and health policy. 2001;4(2):99-108.

27.Schwartz LM, Woloshin S, Welch HG. The drug facts box: providing consumers with simple tabular data on drug benefit and harm. Medical decision making: an international journal of the Society for Medical Decision Making. 2007;27(5):655-62.

28. Woloshin S, Schwartz LM. Communicating data about the benefits and harms of treatment: a randomized trial. Annals of internal medicine. 2011;155(2):87-96.

29.Petrova D, Garcia-Retamero R, Cokely ET. Understanding the Harms and Benefits of Cancer Screening: A Model of Factors That Shape Informed Decision Making. Medical decision making: an international journal of the Society for Medical Decision Making. 2015;35(7):847-58.

30.Sullivan HW, O'Donoghue AC, Aikin KJ. Communicating Benefit and Risk Information in Direct-toConsumer Print Advertisements: A Randomized Study. Therapeutic innovation \& regulatory science. 2015;49(4):493-502.

31.Lamminpaa R, Vehvilainen-Julkunen K, Schwab U. A systematic review of dietary interventions for gestational weight gain and gestational diabetes in overweight and obese pregnant women. European journal of nutrition. 2018;57(5):1721-36. 
32.0'Brien CM, Grivell RM, Dodd JM. Systematic review of antenatal dietary and lifestyle interventions in women with a normal body mass index. Acta obstetricia et gynecologica Scandinavica. 2016;95(3):25969.

33.Rogozinska E, Chamillard M, Hitman GA, Khan KS, Thangaratinam S. Nutritional manipulation for the primary prevention of gestational diabetes mellitus: a meta-analysis of randomised studies. PloS one. 2015;10(2):e0115526.

34.Tanentsapf I, Heitmann BL, Adegboye AR. Systematic review of clinical trials on dietary interventions to prevent excessive weight gain during pregnancy among normal weight, overweight and obese women. BMC pregnancy and childbirth. 2011;11:81.

35.Tieu J, Shepherd E, Middleton P, Crowther CA. Dietary advice interventions in pregnancy for preventing gestational diabetes mellitus. The Cochrane database of systematic reviews. 2017;1:CD006674.

36.Zhang R, Han S, Chen GC, Li ZN, Silva-Zolezzi I, Pares GV, et al. Effects of low-glycemic-index diets in pregnancy on maternal and newborn outcomes in pregnant women: a meta-analysis of randomized controlled trials. European journal of nutrition. 2018;57(1):167-77.

37.da Silva SG, Ricardo LI, Evenson KR, Hallal PC. Leisure-Time Physical Activity in Pregnancy and Maternal-Child Health: A Systematic Review and Meta-Analysis of Randomized Controlled Trials and Cohort Studies. Sports Med. 2017;47(2):295-317.

38. Han S, Middleton P, Crowther CA. Exercise for pregnant women for preventing gestational diabetes mellitus. The Cochrane database of systematic reviews. 2012(7):CD009021.

39.Sanabria-Martinez G, Garcia-Hermoso A, Poyatos-Leon R, Alvarez-Bueno C, Sanchez-Lopez M, Martinez-Vizcaino V. Effectiveness of physical activity interventions on preventing gestational diabetes mellitus and excessive maternal weight gain: a meta-analysis. BJOG: an international journal of obstetrics and gynaecology. 2015;122(9):1167-74.

40.Zheng J, Wang $\mathrm{H}$, Ren M. Influence of exercise intervention on gestational diabetes mellitus: a systematic review and meta-analysis. Journal of endocrinological investigation. 2017;40(10):1027-33.

41.Bennett CJ, Walker RE, Blumfield ML, Gwini SM, Ma J, Wang F, et al. Interventions designed to reduce excessive gestational weight gain can reduce the incidence of gestational diabetes mellitus: A systematic review and meta-analysis of randomised controlled trials. Diabetes research and clinical practice. 2018;141:69-79.

42.Oteng-Ntim E, Varma R, Croker H, Poston L, Doyle P. Lifestyle interventions for overweight and obese pregnant women to improve pregnancy outcome: systematic review and meta-analysis. BMC medicine. 2012;10:47. 
43.Ruifrok AE, Rogozinska E, van Poppel MN, Rayanagoudar G, Kerry S, de Groot CJ, et al. Study protocol: differential effects of diet and physical activity based interventions in pregnancy on maternal and fetal outcomes-individual patient data (IPD) meta-analysis and health economic evaluation. Systematic reviews. 2014;3:131.

44.Shepherd E, Gomersall JC, Tieu J, Han S, Crowther CA, Middleton P. Combined diet and exercise interventions for preventing gestational diabetes mellitus. The Cochrane database of systematic reviews. 2017;11:CD010443.

45.Song C, Li J, Leng J, Ma RC, Yang X. Lifestyle intervention can reduce the risk of gestational diabetes: a meta-analysis of randomized controlled trials. Obesity reviews: an official journal of the International Association for the Study of Obesity. 2016;17(10):960-9.

46.Thangaratinam S, Rogozinska E, Jolly K, Glinkowski S, Roseboom T, Tomlinson JW, et al. Effects of interventions in pregnancy on maternal weight and obstetric outcomes: meta-analysis of randomised evidence. BMJ. 2012;344:e2088.

47.group Realwmipc. Effect of diet and physical activity based interventions in pregnancy on gestational weight gain and pregnancy outcomes: meta-analysis of individual participant data from randomised trials. BMJ. 2017;358:j3991.

48. Moher D, Liberati A, Tetzlaff J, Altman DG, Group P. Preferred reporting items for systematic reviews and meta-analyses: the PRISMA statement. BMJ. 2009;339:b2535.

49.Whiting P, Savovic J, Higgins JP, Caldwell DM, Reeves BC, Shea B, et al. ROBIS: A new tool to assess risk of bias in systematic reviews was developed. Journal of clinical epidemiology. 2016;69:225-34.

50.Shea BJ, Grimshaw JM, Wells GA, Boers M, Andersson N, Hamel C, et al. Development of AMSTAR: a measurement tool to assess the methodological quality of systematic reviews. BMC medical research methodology. 2007;7:10.

51.Shea BJ, Reeves BC, Wells G, Thuku M, Hamel C, Moran J, et al. AMSTAR 2: a critical appraisal tool for systematic reviews that include randomised or non-randomised studies of healthcare interventions, or both. BMJ. 2017;358:j4008.

52.McDowell M, Rebitschek FG, Gigerenzer G, Wegwarth O A simple tool for communicating the benefits and harms of health interventions: A guide for creating a fact box.. MDM P\&P 2016;1:1-10.

53.Sackett DL, Rosenberg WM, Gray JA, Haynes RB, Richardson WS. Evidence based medicine: what it is and what it isn't. BMJ. 1996;312(7023):71-2.

54.Gigerenzer G. Full disclosure about cancer screening. BMJ. 2016;352:h6967. 
55.Arabin B, Timmesfeld N, Noever K, Behnam S, Ellermann C, Jenny MA. How to improve health literacy to reduce short- and long-term consequences of maternal obesity? The journal of maternal-fetal \& neonatal medicine: the official journal of the European Association of Perinatal Medicine, the Federation of Asia and Oceania Perinatal Societies, the International Society of Perinatal Obstet. 2018:1-8.

56.Arabin B. Irresponsible and responsible resource management in obstetrics. Best practice \& research Clinical obstetrics \& gynaecology. 2017;43:87-106.

57.Zhang C, Ning Y. Effect of dietary and lifestyle factors on the risk of gestational diabetes: review of epidemiologic evidence. The American journal of clinical nutrition. 2011;94(6 Suppl):1975S-9S.

58.Bao W, Tobias DK, Hu FB, Chavarro JE, Zhang C. Pre-pregnancy potato consumption and risk of gestational diabetes mellitus: prospective cohort study. BMJ. 2016;352:h6898.

59.Bowers K, Tobias DK, Yeung E, Hu FB, Zhang C. A prospective study of prepregnancy dietary fat intake and risk of gestational diabetes. The American journal of clinical nutrition. 2012;95(2):446-53.

60.Zhang C, Liu S, Solomon CG, Hu FB. Dietary fiber intake, dietary glycemic load, and the risk for gestational diabetes mellitus. Diabetes care. 2006;29(10):2223-30.

61.Bao W, Bowers K, Tobias DK, Hu FB, Zhang C. Prepregnancy dietary protein intake, major dietary protein sources, and the risk of gestational diabetes mellitus: a prospective cohort study. Diabetes care. 2013;36(7):2001-8.

62.Tobias DK, Zhang C, Chavarro J, Bowers K, Rich-Edwards J, Rosner B, et al. Prepregnancy adherence to dietary patterns and lower risk of gestational diabetes mellitus. The American journal of clinical nutrition. 2012;96(2):289-95.

63. Owe KM, Nystad W, Bo K. Association between regular exercise and excessive newborn birth weight. Obstetrics and gynecology. 2009;114(4):770-6.

64. Hegaard HK, Petersson K, Hedegaard M, Ottesen B, Dykes AK, Henriksen TB, et al. Sports and leisuretime physical activity in pregnancy and birth weight: a population-based study. Scandinavian journal of medicine \& science in sports. 2010;20(1):e96-102.

65.Evenson KR, Wen F. Prevalence and correlates of objectively measured physical activity and sedentary behavior among US pregnant women. Preventive medicine. 2011;53(1-2):39-43.

66.Domingues MR, Barros AJ. Leisure-time physical activity during pregnancy in the 2004 Pelotas Birth Cohort Study. Revista de saude publica. 2007;41(2):173-80.

67.Elmaraezy A, Abushouk Al, Emara A, Elshahat O, Ahmed H, M IM. Effect of metformin on maternal and neonatal outcomes in pregnant obese non-diabetic women: A meta-analysis. Int J Reprod Biomed (Yazd). 2017;15(8):461-70. 
68.Crawford TJ, Crowther CA, Alsweiler J, Brown J. Antenatal dietary supplementation with myo-inositol in women during pregnancy for preventing gestational diabetes. The Cochrane database of systematic reviews. 2015(12):CD011507.

69.Barrett HL, Dekker Nitert M, Conwell LS, Callaway LK. Probiotics for preventing gestational diabetes. The Cochrane database of systematic reviews. 2014(2):CD009951.

70.Kalafat E, Sukur YE, Abdi A, Thilaganathan B, Khalil A. Metformin for prevention of hypertensive disorders of pregnancy in women with gestational diabetes or obesity: systematic review and metaanalysis of randomized trials. Ultrasound in obstetrics \& gynecology: the official journal of the International Society of Ultrasound in Obstetrics and Gynecology. 2018;52(6):706-14.

71.Shennan AH, Suff N. Inconclusive evidence for optimal preterm birth prevention. BJOG: an international journal of obstetrics and gynaecology. 2019;126(5):568.

72.Prior M, Hibberd R, Asemota N, Thornton JG. Inadvertent P-hacking among trials and systematic reviews of the effect of progestogens in pregnancy? A systematic review and meta-analysis. BJOG: an international journal of obstetrics and gynaecology. 2017;124(7):1008-15.

73. Higgins J AD, Sterne J.. Chapter 8: Assessing risk of bias in included studies. In: Collaboration TC, editor. Cochrane Handbook for Systematic Reviews of Interventions Version 5.1. 0 (updated March 2011) 2011.

74.Rogozinska E, D'Amico MI, Khan KS, Cecatti JG, Teede H, Yeo S, et al. Development of composite outcomes for individual patient data (IPD) meta-analysis on the effects of diet and lifestyle in pregnancy: a Delphi survey. BJOG: an international journal of obstetrics and gynaecology. 2016;123(2):190-8.

75.Berwick DM, Hackbarth AD. Eliminating waste in US health care. Jama. 2012;307(14):1513-6.

76.Berwick DM, Nolan TW, Whittington J. The triple aim: care, health, and cost. Health Aff (Millwood). 2008;27(3):759-69.

\section{Tables}

Table 1) Summary of 4/17 systematic reviews and meta-analyses (35, 38, 44, 47) investigating lifestyle interventions to reduce gestational diabetes (GDM) and associated health outcomes. According to PRISMA only these 4 studies received 5 points allocated to each element (study question, literature search, data extraction, evaluation of results and registration) (48). 


\begin{tabular}{|c|c|c|c|c|c|c|c|}
\hline $\begin{array}{l}\text { Authors / } \\
\text { integrated } \\
\text { studies / Type } \\
\text { of publication }\end{array}$ & Characteristics & \begin{tabular}{|l|} 
Specified \\
intervention
\end{tabular} & $\begin{array}{l}\text { Effect on } \\
\text { GDM } \\
\text { RR or OR } \\
(95 \% C I)\end{array}$ & $\begin{array}{l}\text { Fetal effects } \\
\text { RR (95\%CI) }\end{array}$ & $\begin{array}{l}\text { Other } \\
\text { significant } \\
\text { effects } \\
\\
\text { RR/MD } \\
(95 \% \mathrm{CI})\end{array}$ & \begin{tabular}{|c|}
$\begin{array}{l}\text { Substantial } \\
\text { heterogeneity }\end{array}$ \\
$\mathrm{I}^{2}$
\end{tabular} & \begin{tabular}{|l|} 
Quality \\
according \\
to \\
ROBIS \\
criteria \\
\\
AMSTAR- \\
1 \& 2 \\
tools \\
\end{tabular} \\
\hline $\begin{array}{l}\text { Tieu et al. } 2017 \\
n=11 \\
\text { Systematic } \\
\text { review and } \\
\text { meta-analysis }\end{array}$ & $\begin{array}{l}\mathrm{n}=2786 \\
\text { All BMI } \\
\text { categories, } \\
\text { subgroups by } \\
\text { BMI }\end{array}$ & \begin{tabular}{|l|} 
Dietary \\
advice, low \\
GI, high \\
fiber
\end{tabular} & $\begin{array}{l}\text { Trend } \\
\text { towards } \\
\text { lower rate } \\
\text { of GDM } \\
\text { RR=0.60 } \\
(0.35-1.04)\end{array}$ & $\begin{array}{c}\text { No data } \\
\text { available }\end{array}$ & $\begin{array}{l}\text { Reduced } \\
\text { gestational } \\
\text { hypertension } \\
\text { RR=0.30 } \\
(0.10-0.88) \\
\text { and weight } \\
\text { gain } \\
\text { MD=-4.70 kg } \\
(-8.07-1.34)\end{array}$ & $\mathrm{I} \square=56 \%$ & \begin{tabular}{|l|}
$\begin{array}{l}\text { Low risk } \\
\text { of bias }\end{array}$ \\
$11 / 11$ \\
$\& \quad 15 / 16$
\end{tabular} \\
\hline $\begin{array}{l}\text { Han et al. } \\
2012 \quad n=5 \\
\text { Systematic } \\
\text { review and } \\
\text { meta-analysis }\end{array}$ & $\begin{array}{l}\mathrm{n}=1115 \\
\text { All BMI } \\
\text { categories }\end{array}$ & $\begin{array}{l}\text { Exercise } \\
\text { not } \\
\text { specified }\end{array}$ & $\begin{array}{l}\text { No } \\
\text { significant } \\
\text { differences } \\
\\
\mathrm{RR}=1.10 \\
(0.7-1.84)\end{array}$ & \begin{tabular}{|l} 
No \\
significant \\
differences
\end{tabular} & $\begin{array}{c}\text { No data } \\
\text { available }\end{array}$ & $\mathrm{I} \square<40$ & \begin{tabular}{|l|}
$\begin{array}{l}\text { Low risk } \\
\text { of bias }\end{array}$ \\
$10 / 11$ \\
$\& \quad 12 / 16$ \\
\end{tabular} \\
\hline $\begin{array}{l}\text { International } \\
\text { weight } \\
\text { management in } \\
\text { pregnancy } \\
\text { collabo-rative } \\
\text { group } 2017 \\
\mathrm{n}=36 \\
\text { Systematic } \\
\text { review and } \\
\text { meta-analysis }\end{array}$ & $\begin{array}{l}\mathrm{n}=12526 \\
\text { All BMI } \\
\text { categories }\end{array}$ & $\begin{array}{l}\text { Diet \& } \\
\text { physical } \\
\text { activity not } \\
\text { specified }\end{array}$ & $\begin{array}{l}\begin{array}{l}\text { Trend } \\
\text { towards } \\
\text { lower rates } \\
\text { of GDM }\end{array} \\
\text { OR=0.89 } \\
(0.7-1.1)\end{array}$ & $\begin{array}{c}\text { No data } \\
\text { available }\end{array}$ & $\begin{array}{l}\text { Reduced } \\
\text { gestational } \\
\text { weight gain } \\
\text { MD-0.70 } \\
(-0.92-0.48) \\
\text { and } \\
\\
\text { Cesareans } \\
\text { OR=0.91 } \\
(0.83-0.99)\end{array}$ & $\mathrm{I} \square<40$ & \begin{tabular}{|l|} 
Low risk \\
of bias \\
\\
$9 / 11 \& \&$ \\
$12 / 16$
\end{tabular} \\
\hline $\begin{array}{l}\text { Shepherd et al. } \\
2017 \\
\mathrm{n}=23 \\
\text { Systematic } \\
\text { review and } \\
\text { meta-analysis }\end{array}$ & $\begin{array}{l}\mathrm{n}=8918 \\
\text { All BMI } \\
\text { categories }\end{array}$ & $\begin{array}{l}\text { Diet, } \\
\text { physical } \\
\text { activity } \\
\text { not } \\
\text { specified }\end{array}$ & \begin{tabular}{|l|} 
Trend \\
towards \\
lower rates \\
of GDM \\
$\mathrm{RR}=0.85$ \\
$(0.71-1.01)$
\end{tabular} & $\begin{array}{l}\text { Trend } \\
\text { towards } \\
\text { lower rates } \\
\text { of LGA : } \\
\text { RR=0.91 } \\
(0.81-1.07), \\
\text { no } \\
\text { differences } \\
\text { in stillbirth: } \\
\text { RR=0.69 } \\
(0.35-1.36)\end{array}$ & $\begin{array}{l}\text { Reduced } \\
\text { gestational } \\
\text { weight gain } \\
\text { MD -0.89 } \\
(-1.39-0.4)\end{array}$ & $\mathrm{I} \square=42$ & 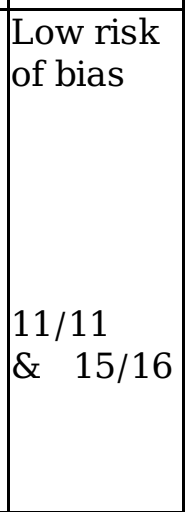 \\
\hline
\end{tabular}

$\mathrm{BMI}=$ body mass index, $\mathrm{CI}=$ confidence interval, $\mathrm{GI}=$ glycemic index, $\mathrm{LGA}=$ large for gestational age, $\mathrm{MD}=\mathrm{mean}$ difference, $\mathrm{OR}=$ odds ratio, $\mathrm{RR}=$ risk ratio, 

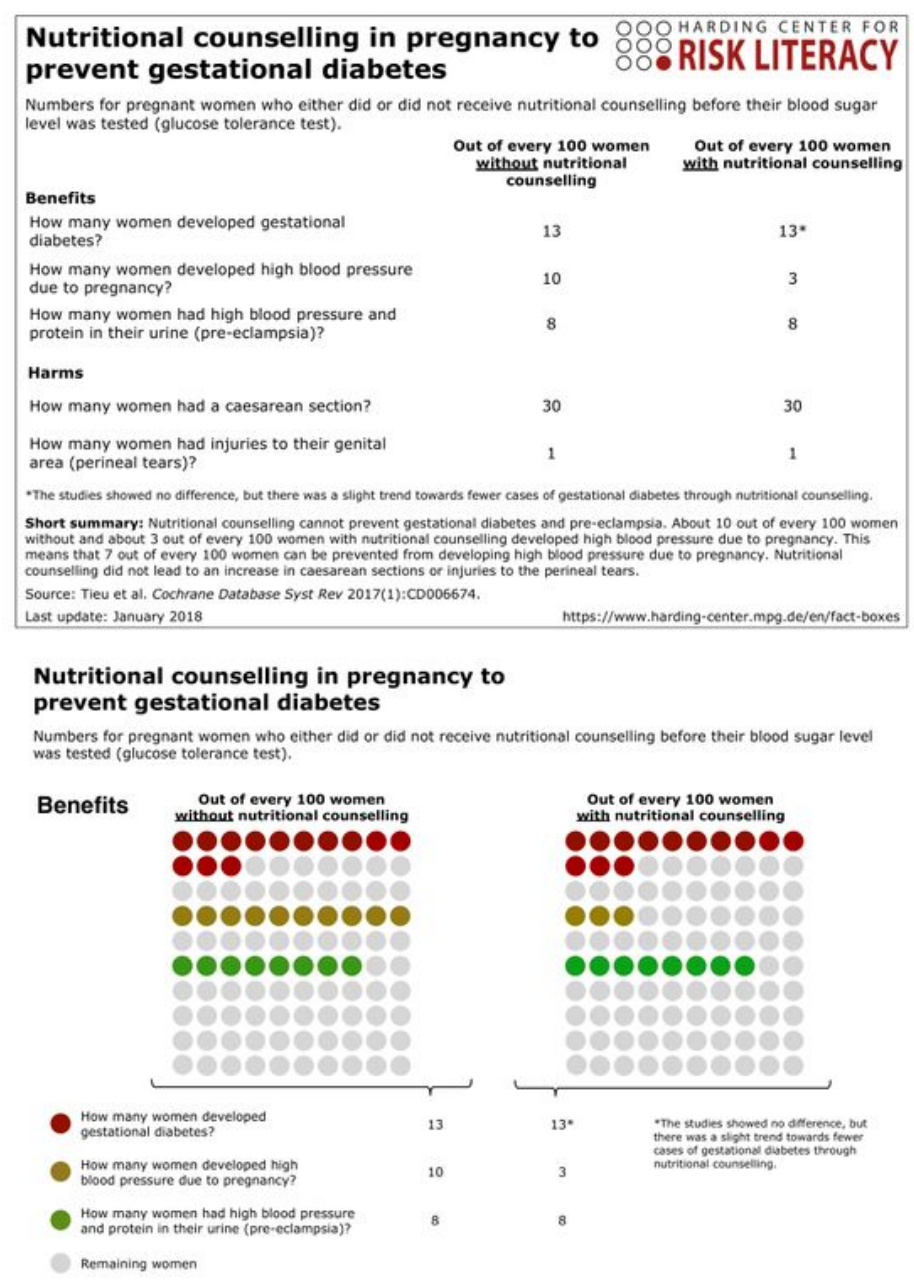

Nutritional counselling in pregnancy to prevent gestational diabetes

Numbers for pregnant women who either did or did not receive nutritional counselling betore their blood sugar level
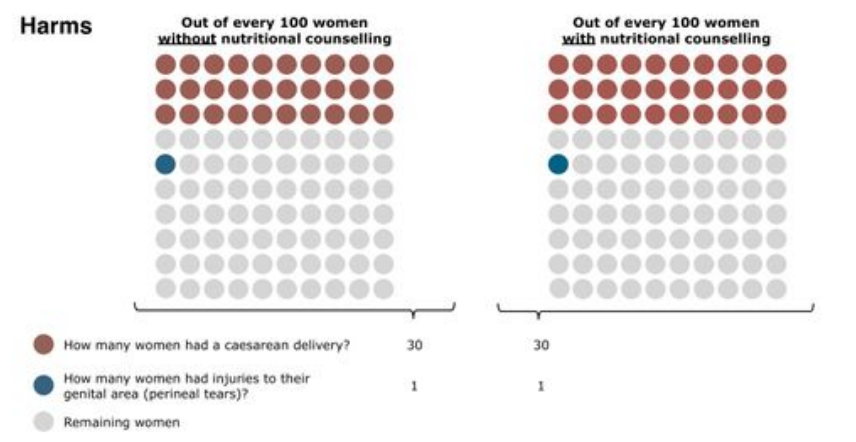

\section{Figure 1}

Fact box combined with an icon array designed to communicate the main patient-relevant benefits and harms of nutritional counselling for pregnant women to prevent gestational diabetes based on the Cochrane Review by Tieu et al. (35). 